Pragmatics 7:2.163-181.

International Pragmatics Association

DOI: $10.1075 /$ prag.7.2.03mat

\title{
NPs IN JAPANESE CONVERSATION ${ }^{1}$
}

\author{
Kazuko Matsumoto
}

\section{Research questions}

This paper is a discourse-pragmatic analysis of nominal phrases (NPs) that speakers of Japanese produce in informal dyadic conversational interaction. More specifically, it examines NPs in terms of their relations to 'intonation units' (Chafe 1987, 1993, 1994) as basic units of discourse production and information flow in spoken discourse.

The present study addresses the following research questions:

(a) What patterns exist in the distribution of NPs within intonation units in conversational Japanese? What relationships exist between the syntactic types of intonation units and NP types?

(b) What is the most preferred NP type in conversational Japanese? NPs of which syntactic form, with which grammatical role, and with which information status do Japanese speakers produce most frequently?

(c) What relationships exist between the information statuses, grammatical roles, and syntactic forms of NPs in conversational Japanese?

(d) Do the 'Given A Constraint' and the 'Non-lexical A Constraint' (Du Bois 1987) hold in conversational Japanese?

\section{Data, transcription, and coding categories}

\subsection{Data and transcription}

The data consists of 16 two-party Japanese conversations, all audiotaped, all face-to-face, and all involving a dyad of young adult native speakers of Tokyo Japanese who know each other very well. Each of the 16 dyadic conversations was transcribed based on the notational conventions provided in Atkinson and Heritage (1984: ix-xvi). The transcribed data were then segmented into 'intonation units' (IUs), which are defined as "sequences of words combined under a single coherent intonation contour" (Chafe 1987: 22), paying

\footnotetext{
${ }^{1}$ This paper is based on part of chapter 5 of my doctoral dissertation submitted to UCLA (Matsumoto 1996). I wish to thank Asif Agha, Roger Andersen, Shoichi Iwasaki, and Sandra Thompson for helfpul comments and suggestions. I also thank Tim Stowell for advice and encouragement.
} 
careful attention to intonation and pausing ${ }^{2}$ (cf. Edwards and Lampert 1993). From each of the 16 transcripts a topically coherent sequence of IUs which contained 100 'substantive' IUs (i.e., IUs which convey substantive ideas of events, states, or referents) (Chafe 1993, 1994) were selected. ${ }^{3}$ The sixteen 100-substantive IU-segments taken from the 16 conversations thus comprised the database for this paper. That is, a total of 1,600 substantive IUs and NPs contained in these IUs were examined for this study. The IUs and NPs were coded using the coding categories given below.

\subsection{Coding categories}

In coding the texts, I used 20 categories for IU syntactic types, 3 categories for information statuses, 6 categories for grammatical roles, and 8 categories for NP syntactic forms. The coding categories are given and defined below.

\subsubsection{Syntactic types of substantive IUs}

I classified the substantive IUs into four major syntactic types, and subdivided the groups into a total of $20 \mathrm{IU}$ syntactic types, as shown below (for examples, see section 3.1 ): ${ }^{4}$

(a) Independent clausal IU: a clausal IU which expresses a complete proposition by itself (subordinate clauses were included in this group). It can be either a full clause consisting of an overt subject and a predicate ([FC]) or a subjectless semi-clause ([PVP]/[PNP $] /[\mathrm{PAP}])$.

$$
[\mathrm{FC}]=\text { overt subject }+ \text { predicate }
$$

\footnotetext{
${ }^{2}$ Of Chafe's (1980) three criteria (i.e., intentional, hesitational, and syntactic) for identifying IUs, I used the intionational criterion as the single most reliable indicator of an IU boundary in this study (cf. Chafe 1993; Cruttenden 1986; Du Bois et al. 1992, 1993; Pierrehumbert and Beckman 1988). In this study I distinguished six intonation contours as signals of IU boundaries. The contours, which marked the end of each IU, are: (a) falling, (b) continuing (with the final syllable unstressed), (c) continuing (with the final syllable stressed), (d) rising, (e) rise-fall, and (f) rise-fall-rise.

${ }^{3}$ The selected segments involving a sequence of 100 substantive IUs included, on the average, 21.1 regulatory IUs (i.e., IUs which function to regulate the flow of conversation, which include discourse markers like sorede 'and' and demo 'but') and 1.2 fragmentary IUs (i.e., IUs which are truncated) (cf. Chafe 1994). This means that of all the IUs contained in the 16 segments, $81 \%$ are substantive, and $19 \%$ are non-substantive (17\% are regulatory).

${ }^{4}$ A clause is defined here as 'a unit of discourse which consists of a predicate and its associated core arguments (i.e., a subject and an object, which may or may not be overtly expressed) and adjuncts (i.e., locative, temporal, and manner adverbials performing circumstantial functions, which are optionally present)' (Chafe 1980; Dixon 1979; Du Bois 1987). A clause is also defined as 'a propositionally complete discourse unit which codes some state or event' (Givón 1990). P in the code [PVP]/[PNP]/[PAP] indicates 'predicate'; $\mathrm{C}$ in the codes [CFC] .... [CXP] indicates 'part of clause'. I coded phrasal IUs as part of a multi-IU clause only when they were produced by the same speaker and only when they were adjacently produced, i.e., when they were not interspersed with other IUs in the transcripts.
} 
$[\mathrm{PVP}]=\varnothing$-subject + verbal predicate

$[\mathrm{PNP}]=\emptyset$-subject + nominal predicate

$[\mathrm{PAP}]=\emptyset$-subject + adjectival predicate

(b) Clausal IU as part of multi-IU clause: a clausal IU which can express a full proposition only in conjunction with other clauses/phrases (e.g., clausal objects of such verbs as yuu 'say' and omou 'think'). As in type (a), it can be either a full clause ([CFC]) or a semi-clause $([\mathrm{CVP}] /[\mathrm{CNP}] /[\mathrm{CAP}])$.

$[\mathrm{CFC}]=$ overt subject + predicate

$[\mathrm{CVP}]=\varnothing$-subject + verbal predicate

$[\mathrm{CNP}]=\emptyset$-subject + nominal predicate

$[\mathrm{CAP}]=\varnothing$-subject + adjectival predicate

(c) Phrasal IU as part of multi-IU clause: a phrasal IU which, together with other clauses/phrases, constitutes a multi-IU clause expressing a complete proposition.

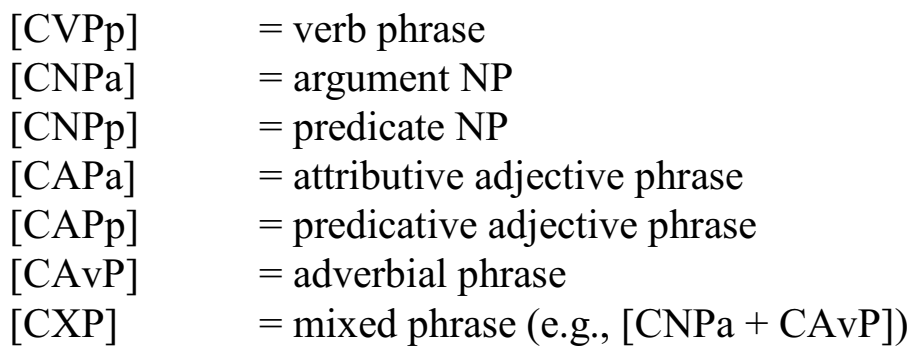

(d) Independent phrasal IU: a phrase which is detached from the clausal structure, thus unlike types (a), (b), and (c), mainly function to perform some 'peripheral' work rather than the 'core' task of communicating propositional content. Included in this group are leftdislocated phrases and postposed phrases (Matsumoto 1995, to appear). ${ }^{5}$

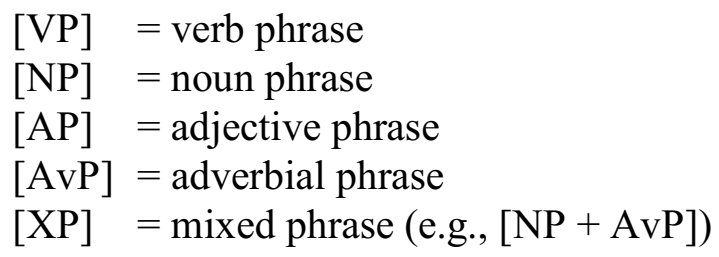

\subsubsection{Information statuses: Given, accessible, and new}

In coding the information statuses of NPs, I used three categories, i.e., given, accessible,

\footnotetext{
${ }^{5}$ I classify the independent phrasal IUs into five types: 'strayed', 'lead', topic/left-dislocated, postposed/right-dislocated, and repeated phrases. I argue that the existence of such clause-external, detached phrases, especially NPs, is important discourse functionally, and that their production is motivated by various discourse communicative, international, and information flow factors (Matsumoto 1997b).
} 
and new. The definitions of the three categories follow (cf. Du Bois 1987: 816):

(a) given: a referent which was mentioned within $25 \mathrm{IUs}^{6}$ previously in the discourse, or a referent which is given from the conversational context itself (e.g., the conversational co-participants) (Chafe 1976).

(b) accessible: a referent which was mentioned more than 25 IUs previously in the discourse, or a referent which was previously unmentioned but is part of a previously evoked schema (Chafe 1987; Du Bois 1980), or a referent which the speaker assumes to be identifiable to the hearer (i.e., to be previously semi-active in the hearer's consciousness) by situation or prior knowledge already shared by the participants.

(c) new: a referent which is neither (a) nor (b), i.e., a referent which was introduced into the discourse as a previously unmentioned, totally new concept.

Given that previous research has found that given and accessible concepts virtually exhibit the same patterning (Du Bois 1987), and accessible mentions appeared rarely in the data, as will be shown below, I will also make a binary distinction between Given and New (with initial capitals), where given and accessible concepts are subsumed under the category Given (the categories New and new refer to identical concepts).

\subsubsection{Grammatical roles: $S, A, O$, and oblique}

In obtaining NP types, I first classified nominals into two broad categories: clause-internal NPs and clause-external NPs. The clause-external NPs refer to NPs contained in the independent phrasal IUs, which, while remaining outside the clausal domain, do not directly participate in the construction of propositions. The clause-internal NPs were further divided into two types: NPs which bear a direct grammatical relation to the verb (i.e., argument NPs) and NPs which do not (i.e., non-argument NPs). The argument NPs consist of three core syntactic-semantic primitives or core grammatical roles, namely, S, A, and O (Comrie 1978; Dixon 1979; Du Bois 1987). The non-argument NPs consist of oblique NPs and predicate nominals which do not seem to directly participate in the structuring of grammatical relations (Du Bois 1987). The six categories of NP grammatical roles are defined below:

(a) S: the single argument of an intransitive verb, i.e., 'intransitive subject', or the subject of a non-verbal (i.e., adjectival/nominal) predicate.

(b) A: the argument of a transitive verb that functions as its subject (and could be the agent NP), i.e., 'transitive subject'.

(c) O: the argument of a transitive verb that functions as its direct object (and could

${ }^{6} \mathrm{Du}$ Bois (1987) uses 20 IUs for this measure in his analysis of the Pear Story Sacapultec narratives, following Givón's (1983) measure of referential distance, and given the one-to-one correspondence between clauses and IUs in his data. I used 25 IUs (20 multiplied by 1.23) instead based on the finding that in my Japanese data one clause contained 1.23 IUs on the average (Matsumoto 1997a). This means that I have chosen 25 IUs as an arbitrary measure during which an active concept will be deactivated into a semi-active state (Chafe 1987). 
be the patient NP), i.e., 'transitive object.."

(d) oblique: clause-internal non-argument NPs other than predicate nominals, which include NPs contained in adverbial phrases, NPs contained in attributive adjectival phrases (mainly NP-no phrases ${ }^{8}$, where no is the genitive case-marking particle), and NPs functioning as topics and complements.

(e) predicate nominals: NPs functioning as predicates.

(f) independent NPs: clause-external NPs contained in independent phrasal IUs (e.g., [XP] IUs).

\subsubsection{Syntactic forms of NPs}

I distinguished the following eight syntactic forms of NPs (simplified codes, which are used in section 3, are given in square brackets). Some observed examples are given for each category.

(a) personal pronouns [p-pro]: atashi/boku/ore 'I', anata 'you', kare 'he', kanojo 'she'.

(b) demonstrative pronoun [d-pro]: kore 'this', sore 'it', are 'that', soo 'so' (as in soo suru/yuu/omou 'do/say/think so').

(c) bare noun [bareN]: NPs which are established dictionary items; gakusei 'student', shinbun 'newspaper', bunka 'culture'.

(d) demonstrative adjective + NP [dem+N]: kono chiiki 'this area', ano hito 'that person', sonna hanashi 'such a story'.

(e) NP-no + NP [N-no+N]: nihon no daigaku 'universities in Japan', Yumiko no tomodachi 'Yumiko's friend'. $+\mathrm{NP})$.

(f) adjective $+\mathrm{NP}[\operatorname{adj}+\mathrm{N}]$ : atarashii eiga 'new movie', ichi-nen 'one year' (numeral

(g) complex NP [compNP]: shiranai hito 'a person whom (you) don't know' (relative clause + NP), inaka tte yuu uwasa 'a rumor that (it is) a rural area' (nominal complement clause $+\mathrm{NP})$.

(h) nominalized VP [nomVP]: sara arau no 'washing dishes' (where no is a moninalizer).

I applied the definitions of the information statuses to all the NPs contained in the 1,600 substantive IUs, which include non-referential predicate nominals which cannot be linked to any specific referents. I also coded NPs contained in intra-IU subordinate clauses and clausal subjects/objects for the three information statuses and surface grammatical role

\footnotetext{
${ }^{7}$ Basically I applied the symbols S/A/O to surface grammatical roles. I thus coded the subject of a passive verb as $\mathrm{S}$ (not $\mathrm{O}$ ). In such constructions as $X$-wa $Y$-ga aru/nai. ' $\mathrm{X}$ has/does not have $\mathrm{Y}$.' and $X$-wa $Y$ ga sukida/wakaru. 'X likes/understands $\mathrm{Y}$.', I coded $\mathrm{X}$ as $\mathrm{A}$, and $\mathrm{Y}$ as $\mathrm{O}$. Typically the roles $\mathrm{S}$ and $\mathrm{A}$ are marked by the particle $g a / w a$, whereas the role $\mathrm{O}$ is marked by the particle $o / w a$, but optionally in casual Japanese conversation.

${ }^{8}$ Of the NP-no phrases produced by the speakers, I coded only those NPs contained in [CAPa] and [CXP] IUs as oblique. Nominals composed of NP-no + NP which appeared in the other IU types were coded as complex wholes with unitary information statuses.
} 
types as well. However, I coded a complex NP (relative clause + NP; nominal complement clause $+\mathrm{NP}$ ) and a nominalized VP as a complex whole with a unitary role and a unitary information status. Further, I coded independent NPs as roleless (without S/A/O), given that they are not clause-internal elements; however, each of them was assigned one of the information statuses.

\section{Results of data analysis}

\subsection{Substantive intonation units and NPs}

My coding revealed that the 1,600 substantive IUs contained 1,417 overt nominals. This means that the average number of NPs that the two conversational co-participants produced while producing 100 substantive IUs is 88.6 . This also means that the average number of NPs contained per substantive IU is 0.89 . This could be interpreted that there almost exists a one-to-one correspondence between substantive IUs and NPs in conversational Japanese, such that one substantive IU contains approximately one overt NP. Table 1 presents the average number of NPs contained per IU by IU syntactic type. Note that the number of NPs listed include that of NPs contained in intra-IU subordinate and embedded clauses. ${ }^{9}$

Table 1 indicates that of the four IU syntactic types, the independent clausal IUs showed the highest rate of NP inclusion, i.e., 0.97 NP per unit on the average. Particularly, single-IU full clauses ([FC] IUs) exhibited the largest average number of NPs, namely, 1.48. The independent semi-clausal IUs with verbal predicates only ([PVP] IUs), although produced most frequently, showed the average of $0.76 \mathrm{NP}$. It also indicates that the majority $(\mathrm{N}=1,242,88 \%)$ of the 1,417 NPs were clause-internal NPs, mostly single-IU clauseinternal NPs $(\mathrm{N}=884,62 \%)$, NPs occurring in single-IU full clauses $(\mathrm{N}=390,28 \%)$, in particular. In short, the results show that the speakers tended to produce NPs as elements of independent single-IU clauses which express a complete proposition, and especially as elements of single-IU full clauses with an overtly-expressed subject and a predicate.

Table 2 displays the distribution of 6 grammatical roles of NPs contained in the 20 IU syntactic types.

Table 2 indicates the following: (a) of the 1,417 NPs contained in the 1,600 substantive IUs, clause-internal argument NPs and non-argument NPs accounted for roughly comparable proportions ( $45 \%$ and $43 \%$, respectively), whereas clause-external independent NPs accounted for only $12 \%$; (b) of the 6 grammatical role types, S roles exhibited the highest percentage (25\%), which is followed in frequency by obliques $(22 \%)$ and predicate nominals (21\%); and (c) only 4\% were A roles, the frequency of which is notably low compared to the other grammatical roles. Of the total number of argument NPs, $56 \%$ were $\mathrm{S}$ roles, $8 \%$ were A roles, and $36 \%$ were $\mathrm{O}$ roles. This suggests that $\mathrm{A}$ is much less likely to be overtly expressed than $\mathrm{S}$ or $\mathrm{O}$ in conversational Japanese, despite the fact that the speakers produced transitive clauses as frequently as intransitive clauses

\footnotetext{
${ }^{9}$ Of the 1,600 substantive IUs, 231 IUs (14\%) contained a total of 244 clauses within themselves (13 IUs contained 2 clauses). The majority of these intra-IU clauses were clausal objects (mostly quotes of thought/speech) and relative clauses. Moreover, the speakers tended to use semi-clauses consisting of verbal predicates within independent single-IU clauses, especially within [PVP] IUs.
} 
(Matsumoto 1997b). Of the non-argument NPs produced, 51\% were obliques, and 49\% were predicate nominals. Further, $90 \%$ of the oblique NPs were NPs in adverbials.

Table 2 also shows that $67 \%$ of the $S$ roles were subjects of independent full clausal IUs ([FC] IUs), $49 \%$ of the A roles were subjects of [FC] IUs, $63 \%$ of the O roles were objects of independent single-IU semi-clauses with verbal predicates only ([PVP] IUs), and $38 \%$ of the oblique NPs were NPs in adverbials contained in [PVP] IUs. In addition, $61 \%$ of the predicate nominals were NPs occurring in independent single-IU semi-clauses with nominal predicates only ([PNP] IUs), and $64 \%$ of the clause-external independent NPs appeared in independent NP IUs ([NP] IUs). This means that, as stated above, the majority of NPs took the form of clause-internal elements of [FC] or [PVP] IUs.

Table 1. The average number of NPs per substantive IU type

IU syntactic type

Number of NPs

Number of IUs

Average number of

NPs per IU

FC

390

PVP

PNP

PAP

Total

CFC

CVP

CNP

CAP

Total

CVPp

CNPa

CNPp

CAPa

CAPp

CAvP

CXP

Total

VP

NP

AP

AvP

XP

Total

TOTAL
297

185

12

884

47

55

18

1

121

11

95

23

15

1

60

32

237

3

112

10

39

11

175

1,417
263

392

174

81

910

40

106
1.48

0.76

1.06

0.15

0.97

1.18

0.52

1.09

0.14

0.71

0.32

1.01

1.00

0.83

0.09

0.67

1.19

0.80

0.43

0.71

0.48

1.38

0.78

0.89
1.00 
Table 2. Distribution of grammatical roles among IU syntactic types

Argument NPs Non-argument NPs

\begin{tabular}{|c|c|c|c|c|c|c|c|}
\hline $\begin{array}{l}\text { IU } \\
\text { type }\end{array}$ & S & A & 0 & Oblique & $\begin{array}{r}\text { Predi- } \\
\text { cate } \\
\text { nominal }\end{array}$ & $\begin{array}{r}\text { Inde- } \\
\text { pendent } \\
\mathrm{NP}\end{array}$ & Total \\
\hline FC & 238 & 27 & 14 & 59 & 52 & -- & 390 \\
\hline PVP & 16 & 5 & 146 & 115 & 15 & -- & 297 \\
\hline PNP & 1 & & 1 & 5 & 178 & -- & 185 \\
\hline PAP & & & 5 & 6 & 1 & -- & 12 \\
\hline Total & 255 & 32 & 166 & 185 & 246 & -- & 884 \\
\hline $\mathrm{CFC}$ & 36 & 5 & & 3 & 3 & -- & 47 \\
\hline CVP & 4 & & 25 & 24 & 2 & -- & 55 \\
\hline $\mathrm{CNP}$ & & & & 1 & 17 & -- & 18 \\
\hline CAP & & & & 1 & & -- & 1 \\
\hline Total & 40 & 5 & 25 & 29 & 22 & -- & 121 \\
\hline CVPp & & & 4 & 6 & 1 & -- & 11 \\
\hline $\mathrm{CNPa}$ & 52 & 15 & 28 & & & -- & 95 \\
\hline CNPp & & & & & 23 & -- & 23 \\
\hline CAPa & & & & 15 & & -- & 15 \\
\hline CAPp & & & & 1 & & -- & 1 \\
\hline CAvP & & & & 60 & & -- & 60 \\
\hline CXP & 11 & 3 & 8 & 10 & & -- & 32 \\
\hline Total & 63 & 18 & 40 & 92 & 24 & -- & 237 \\
\hline $\mathrm{VP}$ & -- & -- & -- & -- & -- & 3 & 3 \\
\hline NP & -- & -- & -- & -- & -- & 112 & 112 \\
\hline $\mathrm{AP}$ & -- & -- & -- & -- & -- & 10 & 10 \\
\hline AvP & -- & -- & -- & -- & -- & 39 & 39 \\
\hline $\mathrm{XP}$ & -- & -- & -- & -- & -- & 11 & 11 \\
\hline Total & -- & -- & -- & -- & -- & 175 & 175 \\
\hline TOTAL & $\begin{array}{r}358 \\
(25 \%)\end{array}$ & $\begin{array}{r}55 \\
(4 \%)\end{array}$ & $\begin{array}{r}231 \\
(16 \%)\end{array}$ & $\begin{array}{r}306 \\
(22 \%)\end{array}$ & $\begin{array}{r}292 \\
(21 \%)\end{array}$ & $\begin{array}{r}175 \\
(12 \%)\end{array}$ & $\begin{array}{l}1,417 \\
(100 \%)\end{array}$ \\
\hline
\end{tabular}

NPs as they occur in substantive IUs are illustrated in the IU sequence $(1),{ }^{10}$ where

\footnotetext{
${ }^{10}$ The following transcription symbols are used in this paper. inter-speaker latching wor- truncated word WORD loud talk
} 

i.S: atashi mo amerika no koto wa shiranai. $=[\mathrm{FC}]$ I also America GEN thing TOP know-NEG 'I don't know about America, either.'
j.Y: $=$ de soko ni $i$ - [fragmentary IU] and there to 'and there -'
k. soko no rokku konsaato ni itte there GEN rock concert to go-and KAetteKONAI. [CVP] return-NEG '(someone) went to a rock concert there and did not come back'
1. to $k a$ itte::, [CVP]
QT Q say-and
'(They) say that'

\subsection{Relationships between grammatical roles, information statuses, and NP syntactic forms}

The relationships between grammatical roles, information statuses, and syntactic forms of NPs are shown in Tables 3, 4, and 5.

Table 3. Grammatical roles and information status

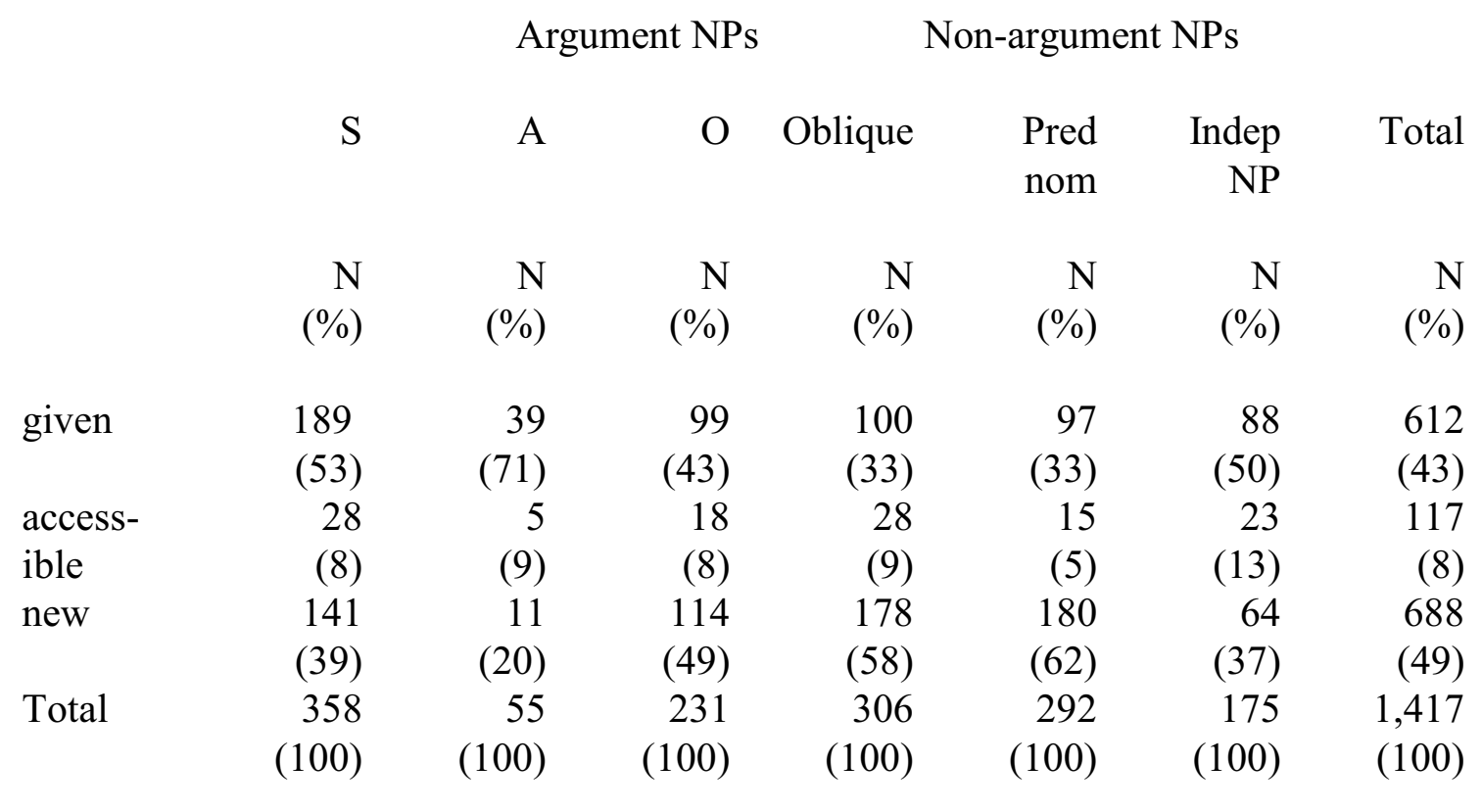

Table 3 indicates that although new NPs exhibited the highest percentage of the three information statuses, accounting for nearly half of the total number of NPs, the proportions of Given (given + accessible) vs. New NPs are roughly comparable, the 
percentage of Given only slightly outnumbering that of New (51\% vs. $49 \%)$. It shows that the use of accessible NPs is the least preferred in conversational Japanese; this is consistent with the results of prior research on narrative discourse (similarly, in Du Bois 1987, only $8 \%$ of the total number of nominal mentions were accessible). Table 3 also indicates the following with respect to the distribution of Given and New information statuses within the 6 grammatical role types: (a) S roles, A roles, and independent NPs tended to be Given; (b) obliques and predicate nominals tended to be New; and (c) $\mathrm{O}$ roles were half Given, and half New ( $51 \%$ vs. $49 \%)$. Further, it shows the following concerning the grammatical roles in which the two information statuses tended to reside: (a) Given information tended to reside in S roles (30\%) or obliques (18\%) (48\% in total); and (b) New information tended to reside in predicate nominals $(26 \%)$ or obliques $(26 \%)(52 \%$ in total).

Several things should be noted in the findings given above concerning the relationships between grammatical roles and information statuses. First, the percentages of New information are notably higher in all role types, compared with, for example, Du Bois's (1987) Sacapultec narrative data (in Du Bois's study, 20\% of the 864 NPs were New, compared to $49 \%$ of the 1,417 NPs in this study). ${ }^{11}$ The higher proportion of New NPs in the Japanese data is clearly attributable to the fact that Given NPs which were maximally attenuated (i.e., not overtly realized) were not coded. This led to the lower percentages of Given NPs, which in turn led to the higher percentages of New NPs. Given the finding that subjectless semi-clausal IUs $([\mathrm{PVP}]+[\mathrm{PNP}]+[\mathrm{PAP}]+[\mathrm{CVP}]+[\mathrm{CNP}]+[\mathrm{CAP}])$ were most prevalent in the data, accounting for $49 \%(\mathrm{~N}=777)$ of the 1,600 substantive IUs (Matsumoto 1997a), this means that at least 777 Given NPs (and probably more if we include $\mathrm{O}$ roles taking zero forms) were not realized in overt forms. We can speculate that if the 777 zero subjects of these semi-clauses had been overtly expressed as pronouns, as is normal in English, the frequency of Given NPs would have been much higher (specifically, it would have increased to 67\%). Second, the finding that the subjects were mostly Given is compatible with Chafe's (1994) 'light subject' constraint. It also indicates that the 'Given A Constraint' (Du Bois 1987) holds in conversational Japanese as well, but not as strongly as in Sacapultec narratives, where $97 \%$ of the A roles were Given. Finally, the tendency of independent NPs to be Given information is compatible with the 'redundant' nature of those clause-external NPs, which are not directly concerned with the communication of propositional content.

Table 4 indicates that of the total number of NPs, (a) $90 \%(\mathrm{~N}=1,270)$ were lexical vs. $10 \%(\mathrm{~N}=147)$ were pronominal; and (b) $50 \%$ were bare nouns without any modifiers, with the other syntactic forms being in low percentages. Most of the pronouns were demonstrative pronouns ( $72 \%$ ) (mostly sore 'it') as opposed to personal pronouns (28\%)

\footnotetext{
${ }^{11}$ The following provides a comparison between the present study and Du Bois (1987) in the percentages of New NPs in four grammatical roles:

$\begin{array}{llllll} & \text { S } & \text { A } & \text { O } & \text { Oblique } & \text { Total } \\ \text { this study } & 39 & 20 & 49 & 58 & 49 \\ \text { Du Bois } & 22 & 3 & 25 & 39 & 20\end{array}$

The higher proportion of New NPs in the Japanese data may also be attributed to the fact that in the Pear Story narratives the number of NPs that could be introduced are more restricted than in informal conversations, in which a wider range of NPs could be introduced.
} 
(mostly 1st person 'I'). Table 4 shows the following concerning the syntactic forms that the 6 grammatical roles tended to take: (a) S roles, O roles, oblique NPs, predicate nominals, and independent NPs tended to be bare nouns; and (b) A roles tended to be bare nouns or personal pronouns. Overall, the speakers exhibited a strong propensity to express the grammatical roles in the form of bare nouns, which accounted for about $40-60 \%$ across the role types.

Table 4. Grammatical roles and syntactic forms of NPs

\begin{tabular}{|c|c|c|c|c|c|c|c|}
\hline & $\mathrm{S}$ & A & $\mathrm{O}$ & Oblique & $\begin{array}{l}\text { Pred } \\
\text { nom }\end{array}$ & $\begin{array}{r}\text { Indep } \\
\mathrm{NP}\end{array}$ & Total \\
\hline & $\begin{array}{r}\mathrm{N} \\
(\%)\end{array}$ & $\begin{array}{r}\mathrm{N} \\
(\%)\end{array}$ & $\begin{array}{r}\mathrm{N} \\
(\%)\end{array}$ & $\begin{array}{r}\mathrm{N} \\
(\%)\end{array}$ & $\begin{array}{r}\mathrm{N} \\
(\%)\end{array}$ & $\begin{array}{r}\mathrm{N} \\
(\%)\end{array}$ & $\begin{array}{r}\mathrm{N} \\
(\%)\end{array}$ \\
\hline p-pro & $\begin{array}{l}15 \\
(4)\end{array}$ & $\begin{array}{r}15 \\
(28)\end{array}$ & $\begin{array}{r}0 \\
(0)\end{array}$ & $\begin{array}{l}10 \\
(3)\end{array}$ & $\begin{array}{r}2 \\
(1)\end{array}$ & $\begin{array}{r}2 \\
(1)\end{array}$ & $\begin{array}{l}44 \\
(3)\end{array}$ \\
\hline d-pro & $\begin{array}{r}47 \\
(13)\end{array}$ & $\begin{array}{r}4 \\
(7)\end{array}$ & $\begin{array}{r}22 \\
(9)\end{array}$ & $\begin{array}{r}11 \\
(3)\end{array}$ & $\begin{array}{r}7 \\
(2)\end{array}$ & $\begin{array}{l}12 \\
(7)\end{array}$ & $\begin{array}{r}103 \\
(8)\end{array}$ \\
\hline bareN & $\begin{array}{l}152 \\
(43)\end{array}$ & $\begin{array}{r}21 \\
(38)\end{array}$ & $\begin{array}{r}122 \\
(53)\end{array}$ & $\begin{array}{l}182 \\
(60)\end{array}$ & $\begin{array}{r}144 \\
(49)\end{array}$ & $\begin{array}{r}91 \\
(52)\end{array}$ & $\begin{array}{r}710 \\
(50)\end{array}$ \\
\hline $\mathrm{dem}+\mathrm{N}$ & $\begin{array}{r}34 \\
(9)\end{array}$ & $\begin{array}{r}5 \\
(9)\end{array}$ & $\begin{array}{r}22 \\
(9)\end{array}$ & $\begin{array}{r}34 \\
(11)\end{array}$ & $\begin{array}{r}19 \\
(7)\end{array}$ & $\begin{array}{r}18 \\
(10)\end{array}$ & $\begin{array}{r}132 \\
(9)\end{array}$ \\
\hline N-no+N & $\begin{array}{r}35 \\
(10)\end{array}$ & $\begin{array}{r}5 \\
(9)\end{array}$ & $\begin{array}{c}18 \\
(8)\end{array}$ & $\begin{array}{l}21 \\
(7)\end{array}$ & $\begin{array}{r}36 \\
(12)\end{array}$ & $\begin{array}{r}16 \\
(9)\end{array}$ & $\begin{array}{r}131 \\
(9)\end{array}$ \\
\hline $\operatorname{adj}+\mathrm{N}$ & $\begin{array}{r}31 \\
(9)\end{array}$ & $\begin{array}{r}1 \\
(2)\end{array}$ & $\begin{array}{r}28 \\
(12)\end{array}$ & $\begin{array}{r}43 \\
(14)\end{array}$ & $\begin{array}{r}52 \\
(18)\end{array}$ & $\begin{array}{r}17 \\
(10)\end{array}$ & $\begin{array}{c}172 \\
(12)\end{array}$ \\
\hline compNP & $\begin{array}{l}32 \\
(9)\end{array}$ & $\begin{array}{r}4 \\
(7)\end{array}$ & $\begin{array}{r}15 \\
(7)\end{array}$ & $\begin{array}{r}5 \\
(2)\end{array}$ & $\begin{array}{r}30 \\
(10)\end{array}$ & $\begin{array}{r}14 \\
(8)\end{array}$ & $\begin{array}{r}102 \\
(7)\end{array}$ \\
\hline nomVP & $\begin{array}{l}12 \\
(3)\end{array}$ & $\begin{array}{r}0 \\
(0)\end{array}$ & $\begin{array}{r}4 \\
(2)\end{array}$ & $\begin{array}{r}0 \\
(0)\end{array}$ & $\begin{array}{r}2 \\
(1)\end{array}$ & $\begin{array}{r}5 \\
(3)\end{array}$ & $\begin{array}{c}23 \\
(2)\end{array}$ \\
\hline Total & $\begin{array}{r}358 \\
(100)\end{array}$ & $\begin{array}{r}55 \\
(100)\end{array}$ & $\begin{array}{r}231 \\
(100)\end{array}$ & $\begin{array}{r}306 \\
(100)\end{array}$ & $\begin{array}{r}292 \\
(100)\end{array}$ & $\begin{array}{r}175 \\
(100)\end{array}$ & $\begin{array}{l}1,417 \\
(100)\end{array}$ \\
\hline
\end{tabular}

Further, Table 4 indicates the following patterns regarding the grammatical roles that the 8 syntactic forms tended to take: (a) personal pronouns tended to be $\mathrm{S}$ roles $(34 \%)$ or A roles (34\%); (b) demonstrative pronouns tended to be $\mathrm{S}$ roles $(46 \%)$ or O roles $(21 \%)$; (c) bare nouns tended to be obliques $(26 \%)$ or S roles $(21 \%)$; (d) demonstrative adjective + NPs tended to be S roles $(26 \%)$ or obliques $(26 \%)$; (e) NP-no + NPs tended to be predicate nominals $(28 \%)$ or S roles $(28 \%)$; (f) adjective + NPs tended to be predicate nominals $(30 \%)$ or obliques $(25 \%)$; (g) complex NPs tended to be $\mathrm{S}$ roles $(31 \%)$ or 
predicate nominals $(29 \%)$; and (h) nominalized VPs tended to be $\mathrm{S}$ roles $(52 \%)$ or independent NPs $(22 \%)$.

Table 5. Information status and NP syntactic forms

\begin{tabular}{|c|c|c|c|c|}
\hline & given & accessible & new & Total \\
\hline & $\mathrm{N} \quad(\%)$ & $\mathrm{N} \quad(\%)$ & $\mathrm{N} \quad(\%)$ & $(\%)$ \\
\hline p-pro & $44 \quad(7)$ & $\begin{array}{ll}0 & (0)\end{array}$ & $(0)$ & 44 \\
\hline d-pro & 102 (17) & 1 (1) & $\begin{array}{ll}0 & (0)\end{array}$ & 103 \\
\hline bareN & $260 \quad(42)$ & $93 \quad(80)$ & $357 \quad(52)$ & $710 \quad(50)$ \\
\hline $\mathrm{dem}+\mathrm{N}$ & 110 (18) & $5 \quad(4)$ & $17 \quad(2)$ & 132 \\
\hline $\mathrm{N}-\mathrm{no}+\mathrm{N}$ & $29 \quad(5)$ & $5 \quad$ (4) & $97 \quad(14)$ & 131 \\
\hline $\operatorname{adj}+\mathrm{N}$ & $37 \quad(6)$ & $7 \quad(6)$ & 128 (19) & 172 (12) \\
\hline compNP & $20 \quad(3)$ & 5 (4) & 77 (11) & $102 \quad(7)$ \\
\hline nomVP & $10 \quad(2)$ & 1 (1) & $12 \quad(2)$ & $23 \quad(2)$ \\
\hline Total & $612(100)$ & $117(100)$ & $688(100)$ & $1,417(100)$ \\
\hline
\end{tabular}

Table 5 indicates the following about the patterns in the expression of activation cost in conversational Japanese: (a) given information tended to take the form of bare nouns or demonstrative adjective + NPs; (b) accessible information tended to take the form of bare nouns; and (c) new information tended to take the form of bare nouns or adjective + NPs. This means that the Japanese speakers showed a strong tendency to express all three of the activation states of NPs in the form of bare nouns, as they also did with respect to the expression of the grammatical roles. Table 4 also shows the following as to the distribution of Given (given + accessible) vs. New information within the 8 NP syntactic forms: (a) $100 \%$ of personal pronouns and demonstrative pronouns expressed Given information; (b) the overwhelming majority of demonstrative adjective + NPs $(87 \%)$ expressed Given information; (c) overwhelmingly, NP-no + NPs (74\%), adjective + NPs (74\%), and complex NPs (76\%) expressed New information; and (d) bare nouns and nominalized VPs expressed half Given and half New information.

In sum, the major finding regarding the relationships between grammatical roles, information statuses, and NP syntactic forms is that bare nouns (and thus lexical NPs) were used preferentially across grammatical roles and information statuses. Pertinent to this is the infrequent use of pronouns in the data (only $10 \%$ of all overt NPs), which is most likely to be linked to the fact that the majority of Given NPs are not expressed and take zero forms in conversational Japanese. Given that $65 \%$ of the A roles were lexical (35\% were nonlexical, pronominal), it appears that the 'Non-lexical A Constraint' (Du Bois 1987) does not hold in conversational Japanese. This in turn seems to be in accord with the weak applicability of the 'Given A Constraint' in conversational Japanese (i.e., A roles contained a higher percentage of New information) (cf. Iwasaki 1985). However, we need to be 
careful in interpreting the finding in relation to the 'Non-lexical A Constraint'. That is, the constraint does not seem to hold in conversational Japanese, to the extent that we look at overt NPs exclusively. Given that many Given NPs (including A-role NPs), which would have taken pronominal forms in other languages such as English, took zero forms in Japanese, it may be that the constraint actually holds (even though not as strongly as in Du Bois 1987), if we code zero-form A-role NPs as pronominal (as special type of pronouns). The same reasoning would apply to the 'Given A Constraint': the 'Given A Constraint' holds less strongly in Japanese, to the extent that we look at overt NPs only; A roles may be more likely to be Given, if we code zero-form A-role NPs as Given. I will address this issue in the next section.

\subsection{The Given A Constraint, the Non-lexical A Constraint, and information pressure}

Related to the higher proportional occurrence of New information in the present Japanese data is the relatively high ratio of new NPs to IUs or clauses. ${ }^{12}$ That is, an Information Pressure Quotient (IPQ) (Du Bois 1987) turned out to be fairly high, somewhat in contrast to $\mathrm{Du}$ Bois's (1987: 835) prediction that in interactive conversations (as opposed to narratives), especially intimate conversations between family members and close friends, information pressure is often low. The quotients are provided below; this indicates that overall, the data involved higher information pressure conditions than Du Bois's Sacapultec narrative data. ${ }^{13}$

(a) a new argument NP was introduced every 4.21 clauses $(\mathrm{IPQ}=0.24)$, and every 6.02 IUs (IPQ $=0.17)$ on average.

(b) a new non-argument NP was introduced every 2.66 clauses (IPQ $=0.38)$, and 3.79 IUs (IPQ $=0.26)$ on average.

(c) a new NP (argument or non-argument) was introduced every 1.63 clauses $(\mathrm{IPQ}=0.61)$, and 2.33 IUs $(\mathrm{IPQ}=0.43)$ on average.

The high-rate introduction of new nominal information (i.e., a new NP every 1.6 clauses/2.3 IUs) by the Japanese speakers seems to be related to their strategy of not expressing overtly already shared, given information. Assuming that the number of nominals to be expressed in a given conversational space is limited, the so-called 'null argument' strategy is likely to increase the probability that more new nominals will get into the space, taking the place of otherwise overtly expressed given NPs. This will result in the increase in the number of new nominals.

\footnotetext{
${ }^{12}$ The syntactic structure analysis has shown that the 1,600 substantive IUs constituted 1,211 clauses, of which 910 were single-IU clauses comprised of 910 IUs, and 211 were multi-IU clauses comprised of 467 IUs (the remaining 223 IUs were clause-external independent phrasal IUs). Of the 1,211 clauses, 32\% were transitive clauses, whereas 68\% were non-transitive clauses (Matsumoto 1997a, 1997b).

${ }^{13}$ In Du Bois (1987), (a) a new argument NP was introduced every 4.32 clauses (IPQ=0.23) on average (where 'clauses' mean what he calls 'clause cores' which basically correspond to IUs); (b) a new nonargument NP was introduced every 6.45 clauses $(\mathrm{IPQ}=0.16)$ on average; and (c) a new NP (argument + nonargument) was introduced every 2.59 clauses (IPQ=0.39).
} 
Table 6. Proportions of overt vs. null arguments ${ }^{14}$

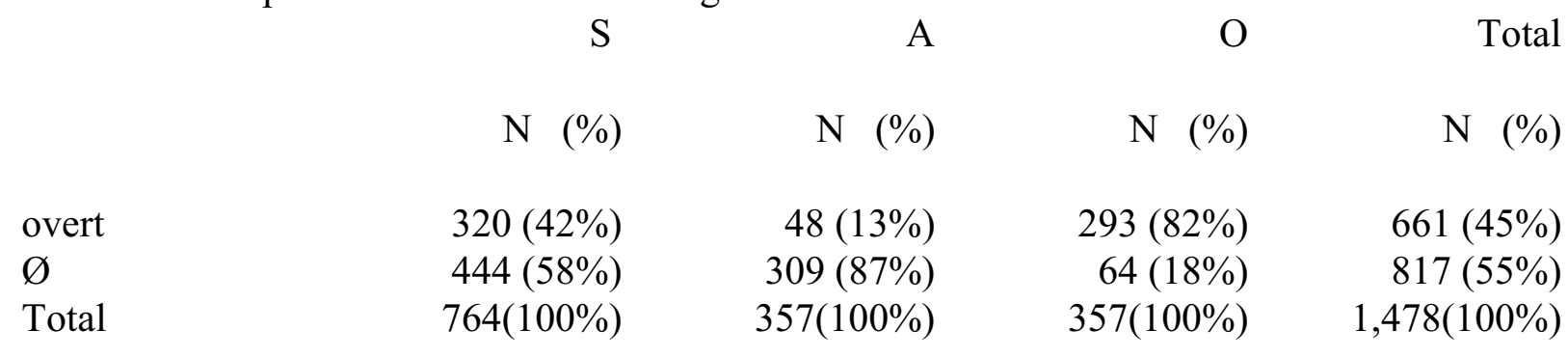

Table 6 presents the proportions of three argument slots that were filled vs. unfilled with overt NPs. In Table $6, \varnothing$ indicates zero arguments, i.e., arguments that are subcategorized by the verb (A and $\mathrm{O}$ for transitive verbs; $\mathrm{S}$ for intransitive verbs and adjectival/nominal predicates) but are not overtly realized. These include both anaphoric zeros (i.e., referential zeros which can be linked with specific referents previously mentioned) and non-anaphoric zeros (i.e., non-referential zeros not derived from prior mentions which always remain non-realized) ${ }^{15}$ (Tao 1993).

Table 6 indicates that of the 1,478 argument slots contained in the 1,121 clauses (which do not include intra-IU clauses; cf. note 12), 45\% were filled with either overt S, $\mathrm{A}$, or $\mathrm{O}$, whereas $55 \%$ received no overt coding, remaining zero. It also indicates an interesting pattern in the overt expressibility of the three roles; that is, O-role slots tend to receive overt coding (which is relevant to the finding that $\mathrm{O}$ roles, in comparison with $\mathrm{A}$ and $\mathrm{S}$ roles, contained more new NPs), whereas S-role and A-role slots tend to remain zero forms. In particular, the finding that the speakers did not fill $87 \%$ of the available A-role slots with overt NPs should be noted. What this suggests is that the transitive subject slot (A), by comparison to the transitive object (O) and intransitive subject (S) slots, is strongly dispreferred as a site for overt NPs. Assuming that new information must always be overt, this in turn means that A-role slots are disfavored for the expression of new nominal referents. In other words, A-role slots constitute preferentially the sites for presupposed, given information. Pertinent to this observation is the speculation that I made above that if the zero-form A roles are coded as Given and as special types of pronouns, both Du Bois's (1987) 'Given A Constraint' and 'Non-lexical A Constraint' will hold in

\footnotetext{
${ }^{14}$ The percentages of filled vs. unfilled S-role slots by clause type are given below. $\begin{array}{lll}\text { Intransitive } & \text { Nominal } & \text { Adjectival }\end{array}$

$\begin{array}{lllll} & \text { Intransitive } & \begin{array}{l}\text { Nominal } \\ \text { predicate }\end{array} & \begin{array}{l}\text { Adjectival } \\ \text { predicate }\end{array} & \text { Total } \\ \text { overt } & 47 & 29 & 51 & 42 \\ \varnothing & 53 & 71 & 49 & 58\end{array}$

${ }^{15}$ The non-anaphoric zero arguments typically appeared in argument slots which would be supplied by generic they and temporal it in English. This means that in constructions involving general statements, time, weather, and so on, Japanese invariably uses zero arguments, just as English uses overt arguments.
} 
conversational Japanese. Given that the overwhelming majority of the A-role NPs took zero-forms, thus Given and pronominal (special type), this seems to lead to the conclusion that the 'Given A Constraint', which was found to hold only weakly, and the 'Non-lexical A Constraint', which was found to be inapplicable, when we looked at overtly expressed NPs only, actually hold in conversational Japanese as well, as in many other languages including Sacapultec (Du Bois 1987), Hebrew (Smith 1996), German (Schuetze-Coburn 1994), French and Spanish (Ashby and Bentivoglio 1993).

\section{Summary}

The results presented above concerning the 1,417 NPs contained in the 1,600 substantive IUs in terms of the three features of grammatical roles, information statuses, and syntactic forms can be summarized as follows (see Table 7). First, overwhelmingly, the speakers produced the NPs as clause-internal argument NPs (45\%) or non-argument NPs $(43 \%)$ ( $88 \%$ in total), and as bare nouns $(50 \%)$. Second, the speakers produced roughly comparable proportions of Given (given + accessible) $(51 \%)$ and New NPs (49\%), with Given NPs slightly outnumbering New NPs. Third, the speakers tended to place Given information in S roles (30\%), oblique NPs (18\%), or O roles (16\%) (64\% in total); and they tended to express Given information in the form of bare nouns (48\%), demonstrative adjective + NPs $(16 \%)$, or demonstrative pronouns (14\%) $(78 \%$ in total). By contrast, the speakers tended to place New information in predicate nominals $(26 \%)$, oblique NPs $(26 \%)$ (i.e., clause-internal non-argument NPs $=52 \%)$, or S roles $(21 \%)(73 \%$ in total); and they tended to express New information in the form of bare nouns $(52 \%)$, adjective + NPs $(19 \%)$, or NP-no + NPs (14\%) (85\% in total). Thus, the most preferred type of overt NPs are bare nouns with S role and with Given information status, and bare nouns with nonargument roles and with New information status.

As discussed above, partly because the fairly large number of Given NPs were not overtly expressed and thus uncoded, the data revealed that the percentage of overtly expressed Given NPs is nearly equal to that of New NPs, and it exhibited as a result the higher proportions of New NPs in all grammatical role types. This suggests that conversational Japanese contains both presupposed and asserted material such that overtly expressed Given and New information exist in equal proportions. Put differently, Japanese conversational co-participants produce and manipulate an approximately equal number of overtly expressed Given and New NPs in communicating propositional content. Although it is normally the case that in languages like English the major portion of discourse consists of given information (anaphoric pronouns) with only a small portion of new information (full NPs) (Givón 1990), in Japanese, which allows abundant zero-form NPs, a smaller amount of overt given information is utilized. This is more economical in the sense that the degree of redundancy produced by repeated expression of given NPs is lowered, and therefore the IU production process is less time-consuming. Another equally significant finding of the present study is that two of Du Bois's (1987) PAS (Preferred Argument Structure) constraints, namely, the 'Given A Constraint' and the 'Non-lexical A Constraint', 
hold in conversational Japanese. ${ }^{16}$

Table 7. Summary of features of 1,417 overt NPs contained in 1,600 substantive IUs

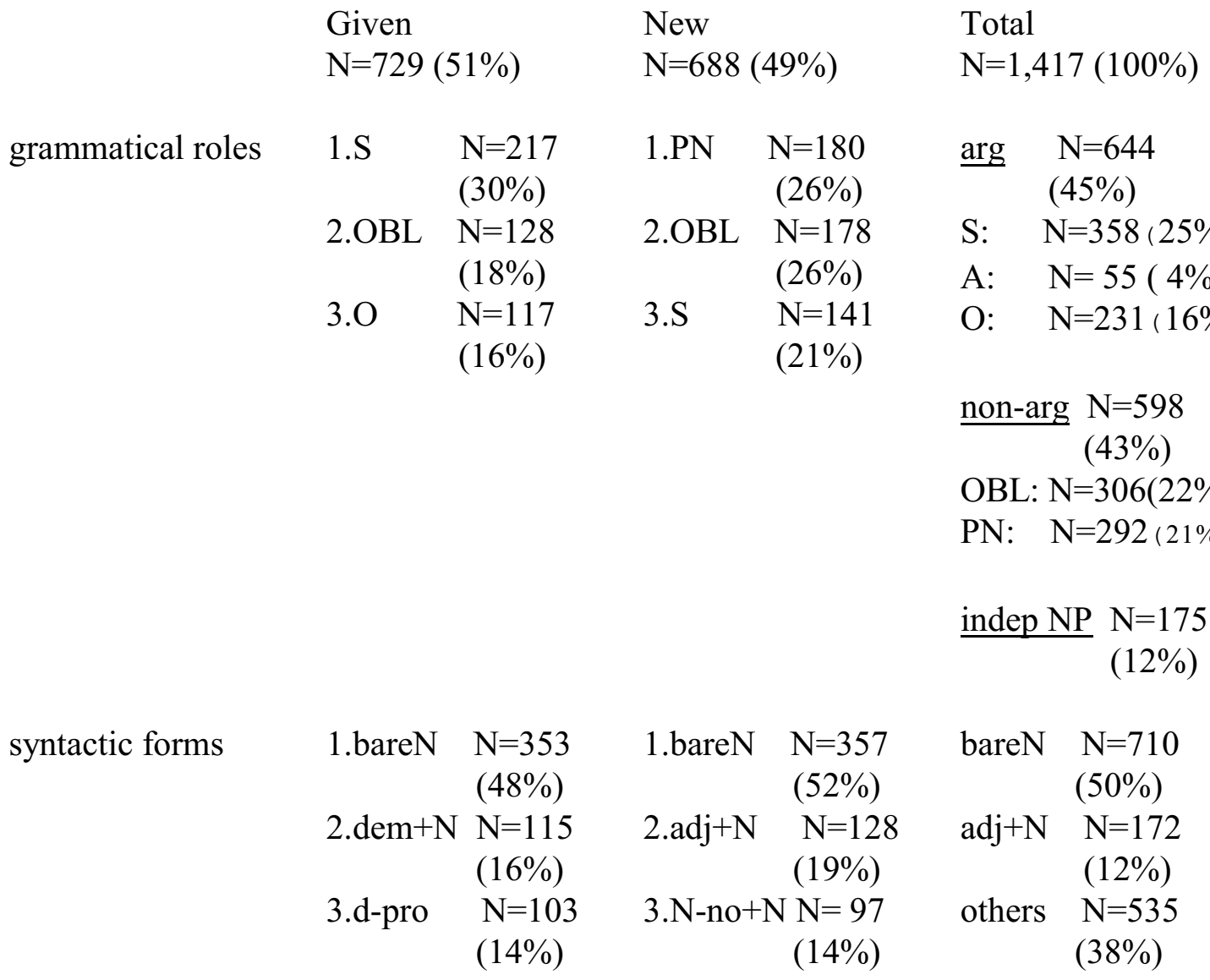

key: $\arg =\operatorname{argument}, \mathrm{OBL}=$ oblique, $\mathrm{PN}=$ predicate nominal, indep $\mathrm{NP}=$ independent $\mathrm{NP}$

\section{References}

Ashby, William J. and Paola Bentivoglio (1993) Preferred argument structure in spoken French and Spanish. Language Variation and Change 5: 61-76.

Atkinson, J. Maxwell and John Heritage (eds.) (1984) Structures of social action: Studies of conversation analysis. Cambridge: Cambridge University Press.

Chafe, Wallace L. (1976) Givenness, contrastiveness, definiteness, subjects, topics, and point of view. In C.

\footnotetext{
${ }^{16}$ For discussion of the preferred information structure of the substantive IU and the preferred clause structure in conversational Japanese, see Matsumoto (1997b).
} 
Li and S. A. Thompson (eds.), Subject and topic. New York: Academic Press, pp. 27-55.

Chafe, Wallace L. (1980) The deployment of consciousness in the production of a narrative. In W. Chafe (ed.), The pear stories: Cognitive, cultural, and linguistic aspects of narrative production. Norwood, NJ: Ablex, pp. 9-50.

Chafe, Wallace L. (1987) Cognitive constraints on information flow. In R. Tomlin (ed.), Coherence and grounding in discourse. Amsterdam: John Benjamins, pp. 21-51.

Chafe, Wallace L. (1993) Prosodic and functional units of language. In J.A. Edwards and M.D. Lampert (eds.), Talking data: Transcription and coding in discourse research. Hillsdale, NJ: Lawrence Erlbaum, pp. 3-43.

Chafe, Wallace L. (1994) Discourse, consciousness, and time: The flow and displacement of conscious experience in speaking and writing. Chicago: University of Chicago Press.

Comrie, Bernard (1978) Ergativity. In W. P. Lehmann (ed.), Syntactic typology. Austin: University of Texas Press, pp. 329-394.

Cruttenden, Alan (1986) Intonation. Cambridge: Cambridge University Press.

Dixon, Robert M. W. (1979) Ergativity. Language 55: 59-138.

Du Bois, John W. (1980) Beyond definiteness: The trace of identity in discourse. In W. Chafe (ed.), The pear stories: Cognitive, cultural, and linguistic aspects of narrative production. Norwood, NJ: Ablex, pp. 203-274.

Du Bois, John W. (1987) The discourse basis of ergativity. Language 63: 805-855.

Du Bois, John W., Stephan Schuetze-Coburn, Susanna Cumming, and Danae Paolino (1993) Outline of discourse transcription. In J.A. Edwards and M.D. Lampert (eds.), Talking data: Transcription and coding in discourse research. Hillsdale, NJ: Lawrence Erlbaum, pp. 45-89.

Du Bois, John W., Stephan Schuetze-Coburn, Danae Paolino, and Susanna Cumming (1992) Discourse transcription: Santa Barbara Papers in Linguistics vol. 4. Department of Linguistics, University of California, Santa Barbara.

Edwards, Jane A. and Martin D. Lampert (eds.) (1993) Talking data: Transcription and coding in discourse research. Hillsdale, NJ: Lawrence Erlbaum.

Givón, Talmy (ed.) (1983) Topic continuity in discourse: A quantitative cross-language study. Amsterdam: John Benjamins.

Givón, Talmy (1990) Syntax vol. II. Amsterdam: John Benjamins.

Iwasaki, Shoichi (1985) The 'Given A Constraint' and the Japanese particle ga. In S. DeLancey and R.S. Tomlin (eds.), Proceedings of the First Annual Pacific Linguistics Conference. Eugene: Department of Linguistics, University of Oregon, pp. 152-167.

Matsumoto, Kazuko (1995) Fragmentation in conversational Japanese. Japan Association for Language Teaching Journal 17: 238-253.

Matsumoto, Kazuko (1996) Intonation units in conversational Japanese: Structure and linkage. Ph.D. dissertation, University of California, Los Angeles.

Matsumoto, Kazuko (1997a) Japanese intonation units and syntactic structure. Paper presented at the 71 st Annual Meeting of the Linguistic Society of America, Chicago, Illinois. 
Matsumoto, Kazuko (1997b) Intonation units and clauses in conversational Japanese: A study of preferred structures. Unpublished manuscript, Aichi University of Education, Aichi, Japan.

Matsumoto, Kazuko (to appear) Detached NPs in Japanese conversation: Types and functions. TEXT.

Pierrehumbert, Janet. B. and Mary Beckman (1988) Japanese tone structure. Cambridge, MA: The MIT Press.

Schuetze-Coburn, Stephan (1994) Prosody, syntax, and discourse pragmatics: Assessing information flow in German conversation. Ph.D. dissertation, University of California, Los Angeles.

Smith, Wendy (1996) Spoken narratives and preferred clause structure: Evidence from modern Hebrew discourse. Studies in Language 20: 163-189.

Tao, Hongyin (1993) Units in Mandarin: Discourse and grammar. Ph.D. dissertation, University of California, Santa Barbara. 